\title{
Technical note: Analytical refinements of the methane indicator archaeol in bovine feces, rumen fluid, and feedstuffs
}

\author{
S. Görs, ${ }^{*}$ B. Kuhla, ${ }^{*}$ N. Krattenmacher,† G. Thaller,† and C. C. Metges ${ }^{* 1}$ \\ *Institute of Nutritional Physiology, Leibniz Institute for Farm Animal Biology (FBN), 18196 Dummerstorf, Germany \\ †Institute of Animal Breeding and Husbandry, Christian-Albrechts University of Kiel, 24118 Kiel, Germany
}

\begin{abstract}
Archaeol (1,2-di-O-phytanyl-sn-glycerol) is a cell membrane lipid component of methanogens that has the potential to be used as a biomarker for methane production in ruminants. However, its analysis via gas chromatography-mass spectrometry (GC-MS) is challenging because of its molecular size and structure. In this study, 2 different sample preparation methods were tested, Soxhlet and sonication-aided extraction, and the methods were compared for extraction efficiency using the internal standard (IS; 1,2-di-o-hexadecyl-rac-glycer$\mathrm{ol}$ ). The extraction efficiency of the Soxhlet method for fecal archaeol was twice that of sonication. With the use of a high-temperature GC column, the retention times of IS and archaeol were 17.6 and $19.4 \mathrm{~min}$, respectively, with a total run time of only $25 \mathrm{~min}$. The molecule ions $m / z 611.4$ (IS) and $m / z 725.8$ (archaeol), or alternatively the fragment ion of the glycerol moiety $\mathrm{m} / \mathrm{z}$ 130.0, were used for identification and quantification via GC-MS in positive chemical ionization mode. The intra-assay coefficients of variation for fecal archaeol measurements were $1.3 \%(\mathrm{~m} / \mathrm{z} 725.8)$ and $2.1 \%(\mathrm{~m} / \mathrm{z}$ 130.0) $(\mathrm{n}=3)$, respectively. Fecal archaeol quantifications did not differ between the use of the molecule or glycerol moiety ions (paired $t$-test, $\mathrm{n}=156$ ). Archaeol concentrations tended to be $3.3 \%$ greater in samples stored at $-20^{\circ} \mathrm{C}$ before drying compared with samples that were immediately dried after collection (paired $t$ test, $\mathrm{n}=5$ ). The detection limit of archaeol was 0.5 $\mu \mathrm{g} / \mathrm{g}$ of fecal dry matter (DM); no archaeol could be detected in feed samples. In different fractions of rumen fluid, archaeol levels ranged from 1.9 to $24.0 \mu \mathrm{g} / \mathrm{g}$ of DM. In 10 cows fed the same grass and corn silage/ hay-based ration, diurnal variations of fecal archaeol levels ( 5 time points over $2 \mathrm{~d}$ ) were cow dependent and ranged from 26.2 to $77.2 \mu \mathrm{g} / \mathrm{g}$ of DM (mean $48.4 \mu \mathrm{g} / \mathrm{g}$
\end{abstract}

Received May 11, 2016.

Accepted June 23, 2016.

${ }^{1}$ Corresponding author: metges@fbn-dummerstorf.de of DM). Thus, within-animal variation in cows on the same diet was between 4 and $27 \%$. We suggest that this finding is related to the amount and time of the latest feed intake event before the fecal sampling. Feeding pattern can determine the passage rate of digesta through the alimentary tract and thus the duration of contact time of archaea with their substrate.

Key words: archaeol, methane biomarker, feces, rumen fluid, dairy cow

\section{Technical Note}

Methane is a greenhouse gas contributing to global warming, and on a global scale, an estimated $17 \%$ is attributable to enteric production, mostly from ruminants (Knapp et al., 2014). The gold standard to quantify methane emission in ruminants is the measurement of individual animals in respiration chambers, which is laborious and does not allow the screening of a large number of animals, especially under farming conditions. Currently, proxies for individual methane emission that are easier to measure are under investigation to provide better estimates for greenhouse gas inventories or phenotypic traits. One of these proxies is archaeol (1,2-di-O-phytanyl-sn-glycerol), a cell membrane lipid constituent of methanogenic microorganisms that is excreted with bovine feces (Gill et al., 2011). The aims of this study were to test the reproducibility and precision of different archaeol analytical methods and to identify analytical refinement factors. A further objective was to investigate whether time of the day of fecal sampling and manner of feces conservation affect archaeol values.

German Holstein dairy cows (average BW of $570 \mathrm{~kg}$, first and second lactation, 100-140 DIM) fed ad libitum a TMR that was composed of (per $\mathrm{kg}$ of DM) $28.4 \%$ grass silage, $14.4 \%$ corn silage, 4 and $8 \%$ grass hay and wheat straw, respectively (17\% RP, $99 \mathrm{~g}$ of starch, $349 \mathrm{~g}$ of NDF, $205 \mathrm{~g}$ of ADF per $\mathrm{kg}$ of feed DM; 6.7 MJ of $\mathrm{NE}_{\mathrm{L}}$; Aguinaga Casañas et al., 2015) were used to sample feces. Two further German Holstein cows equipped with a rumen fistula and fed a similar ration were in their second lactation and at 180 DIM when 
rumen fluid was sampled. All cows were given fresh feed at 0700 and $1500 \mathrm{~h}$ and were milked twice a day at 0630 and $1630 \mathrm{~h}$.

Five rectal grab samples of approximately $200 \mathrm{~g}$ of feces each from 10 cows were collected on 2 consecutive days. Fecal samples were thoroughly mixed and divided into 2 subsamples, one was stored at $-20^{\circ} \mathrm{C}$ until further preparation, and the other was immediately dried at $60^{\circ} \mathrm{C}$ for $72 \mathrm{~h}$, ground $(1 \mathrm{~mm})$, and kept in a cool, dry place. In addition, rumen fluid from 2 cows was sampled at $1000 \mathrm{~h}$ using a tailored device consisting of a syringe attached to a sieve probe that was introduced into the rumen cannula, always at the same depth, to obtain $1 \mathrm{~L}$ of fluid from the saccus ventralis. Rumen fluid was fractionated by filtration and centrifugation into (1) large particles (>2 mm), (2) sifted fraction (1-2 $\mathrm{mm}$ ), (3) protozoa fraction (10 min, $100 \mathrm{~g}$ ), and (4) bacteria fraction $\left(45 \mathrm{~min}, 4^{\circ} \mathrm{C}, 22,800 \mathrm{~g}\right)$. Feed samples [corn silage, soy extract meal, concentrate (MF2000; Getreide AG, Güstrow, Germany), grass hay, dried melassed pellets (rape and corn pulp)] were collected.

Archaeol contents in bovine feces, rumen fluid, and feedstuffs were analyzed by modifications of methods previously published by Bull et al. (2003), Gill et al. (2010, 2011), and McCartney et al. (2013) as follows. Dried and ground (to $1 \mathrm{~mm}$ ) fecal $(1 \mathrm{~g})$, rumen fluid fractions $(1-5 \mathrm{~g})$, and feed $(5 \mathrm{~g})$ samples were spiked with 1,2-di-O-hexadecyl-rac-glycerol $(25 \mu \mathrm{g}$, Santa Cruz Biotechnology Inc., Santa Cruz, CA) as internal standard (IS). The Soxhlet extraction was performed by $200 \mathrm{~mL}$ of dichloromethane (DCM)/acetone (9:1, $\mathrm{vol} / \mathrm{vol}$ ) under reflux for $24 \mathrm{~h}$ using a Soxhlet apparatus according to Gill et al. (2010, 2011) but using about half the amount of IS as reported by McCartney et al. (2013; $43.4 \mu \mathrm{g}$ of IS with $300 \mathrm{mg}$ of sample). The total lipid extract was dried under a gentle $\mathrm{N}_{2}$ stream and saponified with $5 \mathrm{~mL}$ of $5 \mathrm{M} \mathrm{KOH}$ in $90 \%$ methanol for $1 \mathrm{~h}$ at $120^{\circ} \mathrm{C}$. After addition of 10 to $15 \mathrm{~mL}$ ultrapure water, $\mathrm{pH}$ was adjusted to 3 to 4 by addition of $6 \mathrm{M}$ $\mathrm{HCl}$. The saponified total lipid extract was extracted twice with $10 \mathrm{~mL}$ of chloroform, and the solvent of the combined organic phases was evaporated under $\mathrm{N}_{2}$. The residue was dissolved in $5 \mathrm{~mL}$ of DCM/methanol $(2: 1$, $\mathrm{vol} / \mathrm{vol}$ ) and dried by addition of anhydrous $\mathrm{Na}_{2} \mathrm{SO}_{4}$ (Bull et al., 2003). After removing the solvent, the sample was dissolved in $1 \mathrm{~mL}$ of $\mathrm{DCM}$ /isopropanol (2:1, $\mathrm{vol} / \mathrm{vol})$, applied to a pre-eluted (6 $\mathrm{mL}$ of $n$-hexane) solid phase extraction (SPE) column (Strata $\mathrm{NH}_{2} 0.5$ $\mathrm{g} / 6 \mathrm{~mL}$, Phenomenex, Aschaffenburg, Germany), and eluted with $5 \mathrm{~mL}$ of the same solvent mixture. Finally, the solvent was evaporated under $\mathrm{N}_{2}$, and samples were stored at $4^{\circ} \mathrm{C}$.

Lipid extraction by sonication and the removal of polar head groups was performed according to Mc-
Cartney et al. (2013) but with a lower amount of IS. The combined extracts were dried with $\mathrm{Na}_{2} \mathrm{SO}_{4}$ before evaporation. The extract was dissolved in $1 \mathrm{~mL}$ of DCM and purified by elution using a Strata $\mathrm{NH}_{2} \mathrm{SPE}$ column with another $4.5 \mathrm{~mL}$ of DCM.

The cleaned Soxhlet and sonication extracts were derivatized by adding $50 \mu \mathrm{L}$ of pyridine and $50 \mu \mathrm{L}$ of $\mathrm{N}, \mathrm{O}$-bis(trimethylsilyl)trifluoroacetamide containing 1\% trimethylchlorosilane to yield trimethylsilyl (TMS) derivatives (Gill et al., 2010, 2011). The mixture was heated at $70^{\circ} \mathrm{C}$ for $1 \mathrm{~h}$, and solvents were evaporated under a gentle $\mathrm{N}_{2}$ stream. Derivatives were dissolved in $500 \mu \mathrm{L}$ of ethyl acetate and proved to be stable at $-20^{\circ} \mathrm{C}$ for at least 6 mo. They were separated by GC-MS (QP 2010 ULTRA coupled with GC 2010 plus; Shimadzu Deutschland GmbH, Duisburg, Germany) on a $30 \mathrm{~m}$ $\times 0.25 \mathrm{~mm} \times 0.25 \mu \mathrm{m}$ high-temperature column (ZB$5 \mathrm{HT}$, Phenomenex). This method is in contrast to the earlier reports in which no high-temperature columns were used (Gill et al., 2010, 2011; McCartney et al., 2013). The GC was operated with helium as the carrier gas in the flow control mode (linear velocity $45 \mathrm{~cm} / \mathrm{s}$ ). A 1- $\mu \mathrm{L}$ sample was injected (injector AOC-5000 plus, Shimadzu) at a split ratio of 5:1. Injector and interface were held at $280^{\circ} \mathrm{C}$, ion source was set at $200^{\circ} \mathrm{C}$, detector gain at $1.4 \mathrm{kV}$, and emission current at $100 \mu \mathrm{A}$. The GC conditions for separation of the TMS derivatives were $70^{\circ} \mathrm{C}$ held for $1 \mathrm{~min} ; 70-350^{\circ} \mathrm{C}$, increased at $20^{\circ} \mathrm{C} / \mathrm{min}$; and $350^{\circ} \mathrm{C}$ held for $10 \mathrm{~min}$ (total run time 25 min). Mass spectra of IS and archaeol were recorded by selected-ion monitoring after positive chemical ionization (methane), but they were also checked for key ions by a scan in electron impact ionization mode. Archaeol and IS were identified and quantified by their specific molecule ions $m / z 611.4$ and 725.8, respectively, and their retention times of 17.6 and 19.4 min (Figure 1A). Alternatively, quantification was done using ions $\mathrm{m} / \mathrm{z}$ 130.0, representing the glycerol moiety of archaeol and IS alike.

For quantification, calibration curves were constructed by derivatization of $0,10,20,25,30,40,50,60,70$, and $80 \mu \mathrm{g}$ of archaeol (1,2-di-O-phytanyl-sn-glycerol; Avanti Polar Lipids Inc., Alabaster, AL) together with a fixed amount of $25 \mu \mathrm{g}$ IS (1,2-di-O-hexadecyl-racglycerol, corresponds to $50 \mathrm{ng} / \mu \mathrm{L}$ nonderivatized substance injected). The molecule peak area ratios as well as the ratios for the glycerol moiety of archaeol divided by the peak area of IS were plotted against archaeol amounts (Figure 2). The calibration curve was fitted polynomial (TableCurve 2D v5.01.01; Systat Software Inc., Chicago, IL) because the relationship was nonlinear in the lower part of the curve. The resulting equation was used to convert peak area ratios of the samples to archaeol concentrations ( $\mu \mathrm{g} / \mathrm{g}$ of $\mathrm{DM})$ and 
A

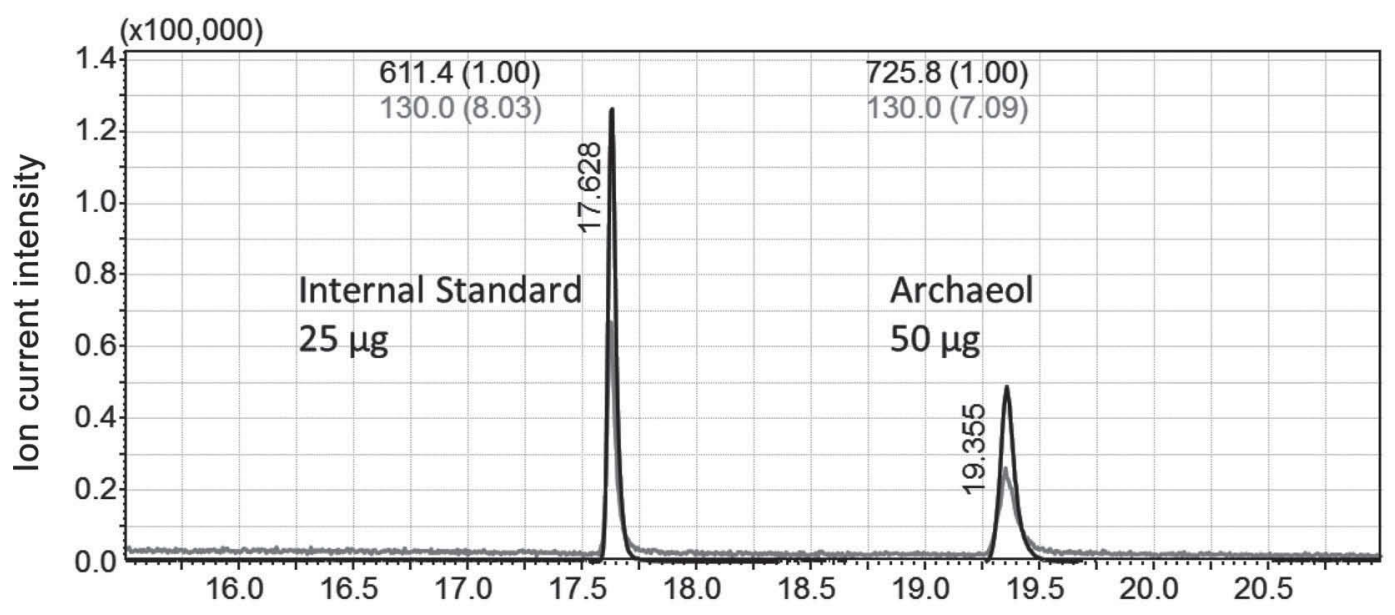

B

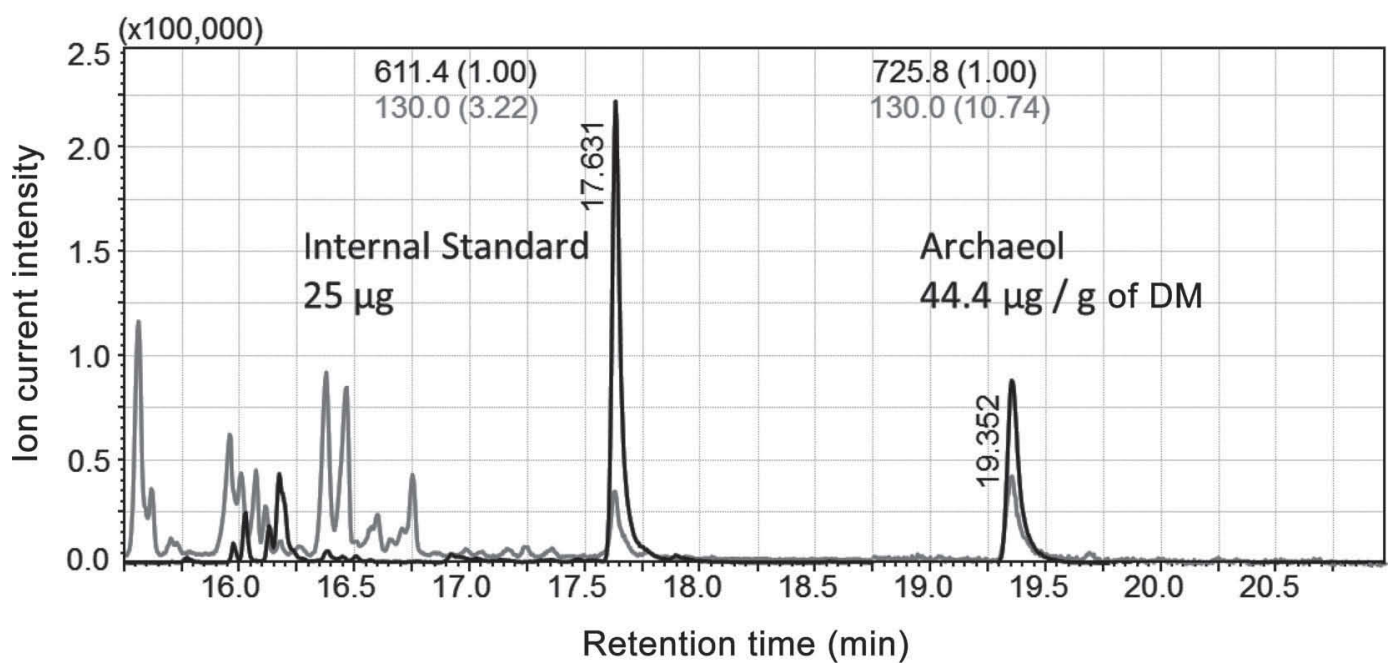

Figure 1. Gas chromatography-MS chromatograms of the internal standard (1,2-di-o-hexadecyl-rac-glycerol, $m / z 611.4)$ and archaeol (1,2-di$O$-phytanyl-sn-glycerol, $m / z$ 725.8) as molecule ions of trimethylsilyl (TMS) derivatives (black curve) and the main fragment of both molecules ( $m / z$ 130.0; gray curve) in GC-MS positive chemical ionization mode. (A) Standard mixture, (B) fecal sample.

was adjusted for each data set. Archaeol quantifications were done with calibrations using archaeol diagnostic ions $m / z 130.0$ or 725.8 (paired $t$-test, $\mathrm{n}=156, P=$ 0.589 ), but we preferred to use the molecule peak ion because of the greater peak areas and absence of signals overlaying the target peaks (Figure 1B).

The lipid extraction procedure with sonication, as reported by McCartney et al. (2013), might require lower volumes of solvents and time in total, but it is more labor intensive than the Soxhlet extraction procedure described by Gill et al. (2010, 2011). Additionally, Soxhlet extraction was more efficient in our hands than the sonication method, and the solvents could be recycled. In a comparison of both extraction methods using the same IS amount $(25 \mu \mathrm{g})$ and GC-MS condi- tions, the IS peak areas were similar $(m / z 611.4$, Soxhlet $65,600 \pm 12,120$ vs. sonication $71,302 \pm 7,177$, each $n$ $=6$, paired $t$-test $P=0.740)$. If the extraction procedures are comparably efficient, the expected archaeol peak area obtained with the sonication method should be $30 \%$ of the peak area obtained with the Soxhlet extraction procedure (100\%) when $0.3 \mathrm{~g}$ and $1 \mathrm{~g}$ of dried feces are used with the sonication method and the Soxhlet procedure, respectively. However, the archaeol peak area measured with the sonication method was only $14 \%$ instead of the expected $30 \%(\mathrm{~m} / z 725.8$, Soxhlet $65,964 \pm 13,554$ vs. sonication $8,988 \pm 1,258$; each $\mathrm{n}=6, P=0.009$ ). Consequently, the resulting calculated archaeol contents in the fecal samples were more than twice as high for the Soxhlet extraction as 


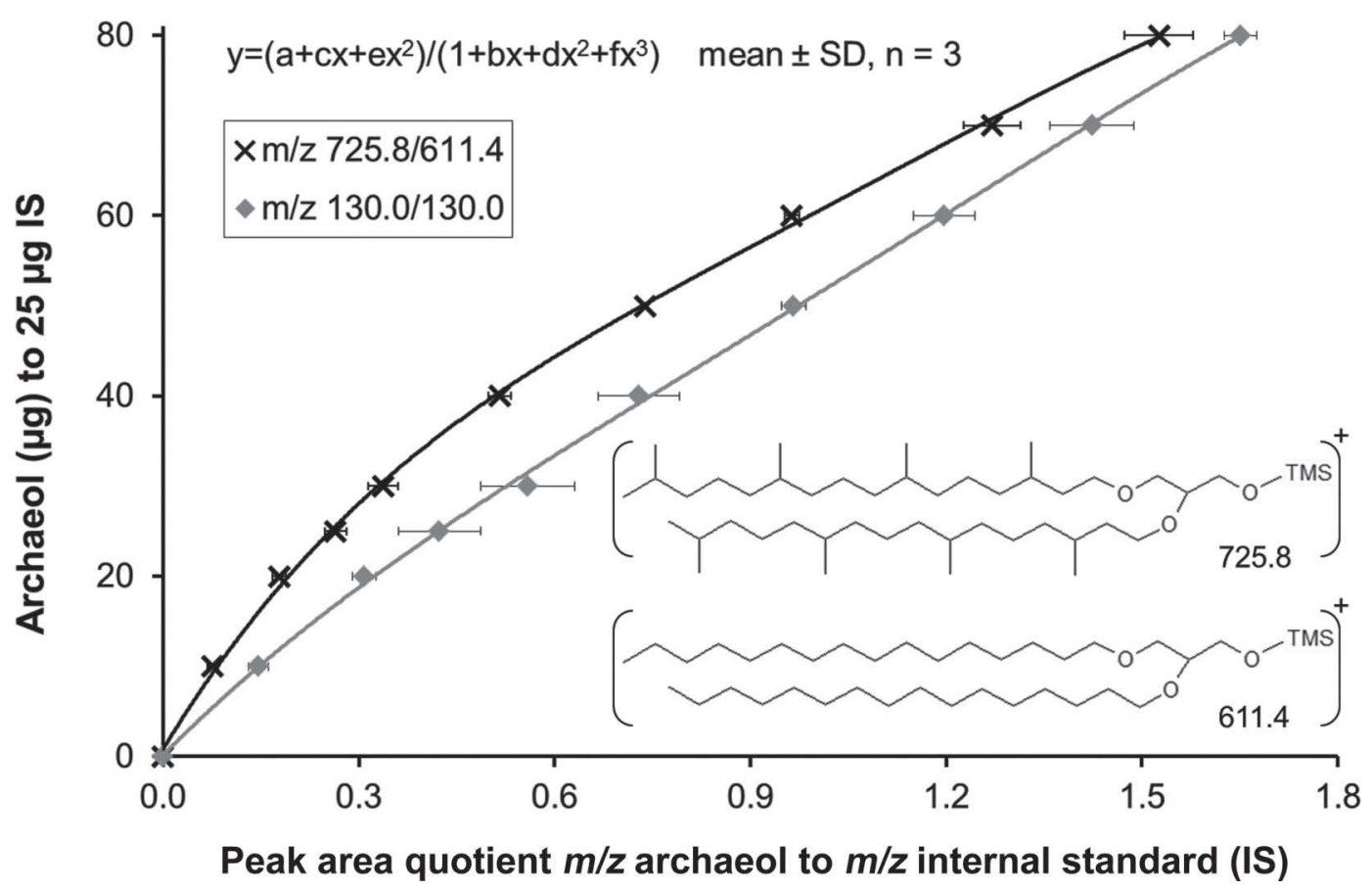

Figure 2. Gas chromatography-MS calibration curve for archaeol (1,2-di-O-phytanyl-sn-glycerol) quantification plotted as amount of archaeol $(\mu \mathrm{g})$ against the quotient of the archaeol molecule ion $(\mathrm{m} / z 725.8)$ peak area divided by the peak area obtained with the internal standard (1,2-di-o-hexadecyl-rac-glycerol, $25 \mu \mathrm{g}$ in each sample) molecule ion $(m / z 611.4)$. Horizontal error bars indicate SD of peak area quotient. Values are means $\pm \mathrm{SD}, \mathrm{n}=3$. TMS $=$ trimethylsilyl.

for the sonication extraction, which is likely because of a more complete breakdown of cell membranes of archeobacteria. In contrast to the procedures described by Gill et al. (2010, 2011) and McCartney et al. (2013), we disclaimed a lipid fractionation (Bull et al., 1999, 2003) because our target substance was contained in the first neutral eluent using the $\mathrm{StrataNH}_{2} \mathrm{SPE}$ column and was sufficiently purified. Because we used a high-temperature column, the total run time of the GC chromatogram was $25 \mathrm{~min}$, which was a reduction by a factor of $>2.5$ compared with the GC run time reported by Gill et al. (2010, 2011) and McCartney et al. (2013). The relatively high amount of sample loaded onto the column was removed from the system at $350^{\circ} \mathrm{C}$ within 10 min at the end of the run.

Three fecal samples were extracted in triplicate, and each extract was measured twice by GC-MS. The mean intra-assay CV of these analyses were $1.3 \%(0.6-3.9)$ with the $m / z 725.8$ calibration and $2.1 \%(0.8-3.8)$ with the $\mathrm{m} / z 130.0$ calibration, respectively. Previous reports on bovine fecal archaeol measurements provide information about the key diagnostic ions for identification, but did not provide calibration details (Gill et al., 2010) or show which diagnostic ions were used to calculate archaeol concentrations (McCartney et al., 2013). To our knowledge, no reports have been published on using the molecule ion $m / z 725.8$ for identification and quantification of archaeol.

Fecal archaeol concentrations (between 39.1 and 71.8 $\mu \mathrm{g} / \mathrm{g}$ of $\mathrm{DM} ; \mathrm{n}=5)$ in samples stored at $-20^{\circ} \mathrm{C}$ before drying tended to be $3.3 \%$ greater than those in samples that were immediately dried after collection (paired $t$ test: $P=0.072$ ). The slightly greater archaeol content measured in previously frozen samples suggests a more complete cell membrane disruption. Archaeol detection limit was $0.5 \mu \mathrm{g} / \mathrm{g}$ of $\mathrm{DM}$ (i.e., $1 \mathrm{ng} / \mu \mathrm{L}$ nonderivatized substance), and archaeol concentrations of feed samples were below the detection limit. In the various rumen fluid fractions, archaeol ranged from 1.9 to $4.7 \mu \mathrm{g} / \mathrm{g}$ of $\mathrm{DM}$ in particles $>2 \mathrm{~mm}$, from 6.9 to $9.3 \mu \mathrm{g} / \mathrm{g}$ of $\mathrm{DM}$ in the 1 - to $2-\mathrm{mm}$ fraction, from 16.7 to $22.9 \mu \mathrm{g} / \mathrm{g}$ of $\mathrm{DM}$ in the protozoa fraction, and from 10.8 to 24.0 $\mu \mathrm{g} / \mathrm{g}$ of DM in the bacteria fraction. Because about $8 \%$ of the total methane emission in cows is released from the rectum (Grainger et al., 2007), we assume that fecal archaeol concentrations reflect the sum of methanogens in the rumen in addition to those of the other sections of the intestinal tract. Thus, the relatively low archaeol concentrations observed in rumen fluid (maximum of $24 \mu \mathrm{g} / \mathrm{g}$ of DM) compared with the fecal archaeol concentrations (Table 1) may indicate that methanogens also colonize the small and large 
Table 1. Diurnal variations and means of fecal archaeol concentrations $(\mu \mathrm{g} / \mathrm{g}$ of DM) in 10 cows when fecal samples were taken on 2 consecutive days at different times of the day

\begin{tabular}{|c|c|c|c|c|c|c|c|c|}
\hline \multirow[b]{2}{*}{ Cow } & \multicolumn{3}{|c|}{ Day 1} & \multicolumn{2}{|c|}{ Day 2} & \multirow[b]{2}{*}{ Mean } & \multirow[b]{2}{*}{ SD } & \multirow[b]{2}{*}{$\mathrm{CV}, \%$} \\
\hline & $0630 \mathrm{~h}$ & $1000 \mathrm{~h}$ & $1430 \mathrm{~h}$ & $0630 \mathrm{~h}$ & $1000 \mathrm{~h}$ & & & \\
\hline 34704 & 37.0 & 36.9 & 41.0 & 45.1 & 37.8 & 39.6 & 3.5 & 8.9 \\
\hline 34739 & 54.2 & 48.4 & 51.3 & 41.1 & 34.3 & 45.9 & 8.1 & 17.6 \\
\hline 49987 & 58.8 & 47.2 & 74.4 & 42.6 & 47.5 & 54.1 & 12.8 & 23.7 \\
\hline 51261 & 58.0 & 41.8 & 52.0 & 48.8 & 26.2 & 45.4 & 12.2 & 27.0 \\
\hline 78382 & 51.3 & 49.3 & 50.4 & 45.5 & 49.4 & 49.2 & 2.2 & 4.5 \\
\hline 94454 & 49.3 & 42.2 & 41.9 & 47.2 & 51.0 & 46.3 & 4.1 & 8.9 \\
\hline 94468 & 51.5 & 53.7 & 46.0 & 51.0 & 53.8 & 51.2 & 3.2 & 6.2 \\
\hline 94548 & 47.7 & 44.7 & 42.6 & 48.1 & 48.2 & 46.3 & 2.5 & 5.4 \\
\hline 94554 & 61.0 & 72.0 & 46.7 & 61.3 & 77.2 & 63.6 & 11.8 & 18.5 \\
\hline 94663 & 46.2 & 39.4 & 42.7 & 41.5 & 42.7 & 42.5 & 2.5 & 5.8 \\
\hline Mean & 51.0 & 47.6 & 48.9 & 47.2 & 46.8 & 48.4 & 1.9 & 3.9 \\
\hline
\end{tabular}

intestine. Indeed, an analysis of rRNA genes indicated that methanogens are resident in the small intestine of cows, albeit to a lower extent than in the rumen (Frey et al., 2010). According to that analysis, the relative abundance of methanogens was $5,1,4.5$, and $1.3 \%$ of total procaryotes in the rumen, duodenum, ileum, and feces, respectively (Frey et al., 2010). Our finding that archaeol concentration was more than 2 times greater in feces than in rumen fluid samples might be explained by extraruminal archaeol contributions adding to rumen-derived archaeol (Frey et al., 2010). Fecal archaeol concentrations obtained from the 10 cows fed the same diet for more than $8 \mathrm{wk}$ ranged between 26.2 and $77.2 \mu \mathrm{g} / \mathrm{g}$ of DM. Within-animal variation of fecal archaeol was cow dependent and amounted to $9 \%$ in low-excreting cows and approximately $19 \%$ in high-excreting cows, with a maximum of $27 \%$ within 27 $\mathrm{h}$ (Table 1). However, in 6 of 10 cows measured, variation over time was below $10 \%$ (Table 1). A reason for the difference in within-animal variation and the level of fecal archaeol concentrations among cows could be related to the amount and time of the latest feed intake event before sampling. The higher the feed intake in a limited period of time, the higher is the passage rate of digesta from the rumen to the rectum. Therefore, the duration of contact between methanogens, other procaryotes, and the feed is reduced, which has been shown to reduce methane emission (Goopy et al., 2014) and thus may be reflected by different archaeol concentrations, within and between animals.

In conclusion, the Soxhlet extraction procedure used herein had superior efficiency to sonication, leading to higher fecal archaeol yields. Archaeol quantification was preferably performed using the archaeol diagnostic ion $m / z 725.8$ because interfering signals were absent. We showed that in rumen fluid, archaeol concentrations were highest in the protozoa and bacterial fractions, but those amounts were only 30 to $50 \%$ of what was measured in feces, which is likely due to extra-ruminal methanogens present in the small and large intestine. Within-animal variation of cows on the same diet was substantial, which requires further study. We suggest that this finding is related to the amount and time of the latest feed intake event before feces sample collection and to changes of passage rate of digesta through the alimentary tract.

\section{ACKNOWLEDGMENTS}

We thank T. Lenke, K. Pilz, D. Oswald, R. Gaeth, and A. Schulz (all of Leibniz Institute for Farm Animal Biology, FBN) for animal feeding and care as well as feces sampling. K. Grot and U. Lüdtke (FBN) are acknowledged for performing the GC-MS analyses. The results reported herein were obtained with financial support from the Federal Ministry of Food and Agriculture (Bonn, Germany), within the framework of the joint project 'MethanA' together with the Institute of Animal Breeding and Husbandry, Christian-AlbrechtsUniversity (Kiel, Germany; 2812NA003). This paper does not necessarily reflect the views of the ministry and in no way anticipates its future policy in this area.

\section{REFERENCES}

Aguinaga Casañas, M. A., N. Rangkasenee, N. Krattenmacher, G. Thaller, C. C. Metges, and B. Kuhla. 2015. Methyl-coenzyme M reductase $\mathrm{A}$ as an indicator to estimate methane production from dairy cows. J. Dairy Sci. 98:4074-4083.

Bull, I. D., M. M. Elhmmali, D. J. Roberts, and R. P. Evershed. 2003. The application of steroidal biomarkers to track the abandonment of a Roman wastewater course at the Agora (Athens, Greece). Archaeometry 45:149-161.

Bull, I. D., I. A. Simpson, S. J. Dockrill, and R. P. Evershed. 1999. Organic geochemical evidence for the origin of ancient anthropogenic soil deposits at Tofts Ness, Sanday, Orkney. Org. Geochem. $30: 535-556$. 
Frey, J. C., A. N. Pell, R. Berthiaume, H. Lapierre, S. Lee, J. K. Ha, J. E. Mendell, and E. R. Angert. 2010. Comparative studies of microbial populations in the rumen, duodenum, ileum and faeces of lactating dairy cows. J. Appl. Microbiol. 108:1982-1993.

Gill, F. L., R. J. Dewhurst, J. A. J. Dungait, R. P. Evershed, L. Ives, C.-S. Li, R. D. Pancost, M. Sullivan, S. Bera, and I. D. Bull. 2010 Archaeol-A biomarker for foregut fermentation in modern and ancient herbivorous mammals? Org. Geochem. 41:467-472.

Gill, F. L., R. J. Dewhurst, R. P. Evershed, E. McGeough, P. O'Kiely, R. D. Pancost, and I. D. Bull. 2011. Analysis of archaeal ether lipids in bovine faeces. Anim. Feed Sci. Technol. 166-167:87-92.

Goopy, J. P., A. Donaldson, R. Hegarty, P. E. Vercoe, F. Haynes, M. Barnett, and V. H. Oddy. 2014. Low-methane yield sheep have smaller rumens and shorter rumen retention time. Br. J. Nutr. 111:578-585.
Grainger, C., T. Clarke, S. M. McGinn, M. J. Auldist, K. A. Beauchemin, M. C. Hannah, G. C. Waghorn, H. Clark, and R. J. Eckard 2007. Methane emissions from dairy cows measured using the sulfur hexafluoride (SF6) tracer and chamber techniques. J. Dairy Sci. 90:2755-2766.

Knapp, J. R., G. L. Laur, P. A. Vadas, W. P. Weiss, and J. M. Tricarico. 2014. Invited review: Enteric methane in dairy cattle production: Quantifying the opportunities and impact of reducing emissions. J. Dairy Sci. 97:3231-3261.

McCartney, C. A., I. D. Bull, T. Yan, and R. J. Dewhurst. 2013. Assessment of archaeol as a molecular proxy for methane production in cattle. J. Dairy Sci. 96:1211-1217. 